\title{
The Pre-Kindergarten Learning Enterprise (PKLE)
}

Kahina Lasfer, Stevens Institute of Technology, USA

Art Pyster, Stevens Institute of Technology and Systems Engineering Research Center, USA

Brian Sauser, Stevens Institute of Technology, USA

\begin{abstract}
To meet the challenges that today's pre-Kindergarten children will face as adults, they need effective development and learning organizations. Together, those organizations form the preKindergarten (pre-K) learning enterprise, whose characteristics and behaviors greatly influence what pre-K children learn and how well they learn it. In this paper, the pre-K learning enterprise is explicitly defined and modeled for the first time and then analyzed through a systems thinking lens using systemigrams and related causal loop diagrams. Defining and modeling the pre-K learning enterprise is itself valuable as a means to understand the various relationships that exist among the identified constituent systems (e.g., home environment, preschool, financial, health care, state, and government) and the stakeholders identified within the enterprise (e.g., parents, educators, health care providers, and policy makers). That value is enhanced through an analysis which reveals the predominant reliance of several key pre-K learning enterprise component systems on the financial system while exposing weak interactions among the three main participating systems (preschools, home environment, and government). Heavy reliance on the financial system in today's economy reduces the effectiveness of the pre-K learning enterprise. To ease such reliance on the financial system while enhancing key interrelationships, three improvements to the existing enterprise are postulated: (1) enhance the role of parents through better education on child development, learning, health and nutrition and their increased voluntary involvement with preschools, (2) reduce the dependency on the financial system and promote partnerships among preschools, sports facilities, libraries and other learning systems to share resources, and (3) enhance government role through implementation of curriculum standardization, assessment and evaluation, and an effective policy towards mandatory education of low-income children.
\end{abstract}

Keywords: pre-kindergarten education; pre-secondary schools; learning enterprise; learning organization

\section{THE PRE-K LEARNING ENTERPRISE (PKLE) - A SYSTEMS APPROACH}

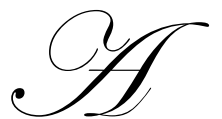

$\mathrm{s}$ the proliferation of formal educational methods moves further into how we educate younger generations (i.e. pre-K), and the importance of science and engineering knowledge becomes foundational in the generations entering college (i.e. 12+), our ability to understand the enterprise that is the locus of their intellectual gestation becomes critical. A true systemic approach finds the root of the problem and addresses it from its source so as to create a more fruitful sink. (Pre-K) Learning Enterprise (PKLE) is comprised of the various organizations and systems that participate in offering a learning environment that allows children to enhance their educational capabilities. As recognized by many experts [DAH01], [KAG06], [KAG01], child preparation for school involves a complex process that requires developing a combination of skills, among them, cognitive, communication, and social skills, as well as good health (physical and mental) and nutrition.

A review of the relevant literature revealed a noticeable lack of studies related to building a PKLE for the preschool environment. Thus, in our study of the PKLE, we believe we are only beginning to address the dynamic interrelationships that make up what we believe to be the simplest of educational systems. In understanding a multiperspective stakeholder view of the PKLE, we were able to capture that understanding by graphical and textual means using a systemic diagram (i.e. systemigram) as the main tool for the PKLE to illustrate these various systems 
and their interrelationships. The systems approach, e.g. as articulated through systemigrams, allows one to look at these entities as a whole to understand the different links between the participating systems.

The systems thinking approach is used to see the big picture rather than pieces and snapshots in a system, identify how parts of a system work together, rather than as a collection of unrelated pieces, and identify how elements in a system influence the patterns of behavior and events to which one reacts. In "The Turning Point", Capra [CAP82] emphasized "The systems view looks at the world in terms of relationships and integration. Systems are integrated wholes whose properties cannot be reduced to those of smaller units." To better handle the complexity of defining the different relationships among participating systems within the PKLE, a Soft Systems Methodology (SSM) [CHE81] is used in the present study. SSM is commonly used to solve complex unstructured problems based on holistic analysis as part of the systems thinking approach that allows relevant stakeholders to understand each other's perspectives [CHE81]. SSM is used to determine the scope of interest by defining systems boundaries, interiors, exteriors, and every other part of the PKLE. The methodology is based on a seven-stage process as illustrated in Figure 1, which starts by clarifying an unstructured or "messy" problem situation through designing ideal or conceptual systems that would help improve the situation. The word "systemigram" originated from two words: "systemic" and "diagram". It was created to diffuse the complexity in communicating the different concepts and their relationships in a system [CHE90].

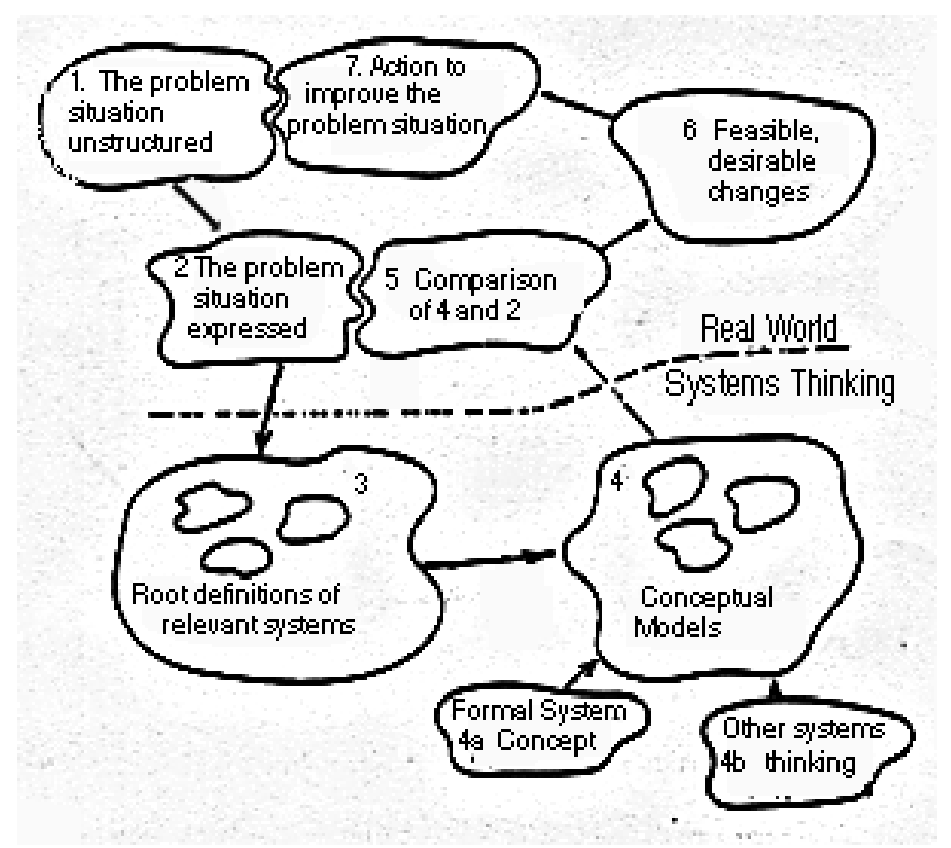

Figure 1: Adapted From Checkland [Che81]

\section{APPLYING SSM TO PKLE}

\section{SSM1 \& 2 - Identifying The constituents Of The PKLE}

The main goal of a PKLE is to continuously and dynamically ensure achievement of the children's learning outcomes. It includes the preschool system comprised of private preschools that are self-sustained and public preschools that are supported by government agencies. Both private and public preschools are certified by the state's legal services. Health care services provide health, safety, and related child development education to children, parents and educators. Most health services are supported financially through health insurance paid by parents or the government. Parents are very sensitive to the health and education of their children and the related budgets. Support activities are offered to reinforce children's cognitive, physical and social development. The educational budget is 
primarily deducted from private tuition and government funding and may depend on the economical conditions and the federal budget allocated to pre-K education.

Table 1 provides a list of PKLE enterprise participating organizations and systems along with their role(s).

Table 1. Participating Systems In The PKLE Enterprise

\begin{tabular}{|c|c|c|}
\hline System & Role & Observations \\
\hline Home environment & $\begin{array}{l}\text { Provides and supports a child's development } \\
\text { and learning }\end{array}$ & $\begin{array}{l}\text { First system contributing to a } \\
\text { child's development and learning } \\
\text { from the child's birth onward }\end{array}$ \\
\hline $\begin{array}{l}\text { Preschools } \\
\text { - Private preschools } \\
\text { - Child Care } \\
\text { - Children with Disabilities } \\
\text { - State Funded prekindergarten } \\
\text { - Head Start }\end{array}$ & Prepare children to enter kindergarten & $\begin{array}{l}\text { Achievement of learning outcomes } \\
\text { is highly dependent on preschool } \\
\text { environment }\end{array}$ \\
\hline $\begin{array}{l}\text { Educational system } \\
\text { - Teachers } \\
\text { - Training } \\
\text { - Curriculum } \\
\end{array}$ & $\begin{array}{l}\text { Provides formal child education, teacher } \\
\text { training and program certification }\end{array}$ & $\begin{array}{l}\text { Educational system assumes a } \\
\text { primary role in developing effective } \\
\text { learning methods. }\end{array}$ \\
\hline Enrichment activities & $\begin{array}{l}\text { Foster positive peer interaction, initiative, } \\
\text { learning, and self-understanding }\end{array}$ & $\begin{array}{l}\text { Complement preschools and } \\
\text { educational systems to achieve the } \\
\text { learning outcomes. }\end{array}$ \\
\hline Multimedia & $\begin{array}{l}\text { Enhance learning through games, books, and } \\
\text { videos }\end{array}$ & $\begin{array}{l}\text { Needs to be used effectively to } \\
\text { contribute to child's learning. }\end{array}$ \\
\hline Parents' education and awareness & $\begin{array}{l}\text { Participation in child's education and with } \\
\text { the schools }\end{array}$ & $\begin{array}{l}\text { Plays an important role to support } \\
\text { the learning outcomes. }\end{array}$ \\
\hline Financial system & $\begin{array}{l}\text { Provides financial support for the schools, } \\
\text { health care, support activities, and the } \\
\text { educational system }\end{array}$ & $\begin{array}{l}\text { Represents the backbone of support } \\
\text { for all other PKLE systems. }\end{array}$ \\
\hline $\begin{array}{l}\text { Government/state/county/township } \\
\text { system }\end{array}$ & $\begin{array}{l}\text { Support the financial system and provide } \\
\text { educational program certification }\end{array}$ & $\begin{array}{l}\text { Vital support specifically for low } \\
\text { income families to offer a better } \\
\text { learning environment for their } \\
\text { children. }\end{array}$ \\
\hline Nutrition and health & Enhance the child's growth and learning & $\begin{array}{l}\text { Complement the child's overall } \\
\text { development. }\end{array}$ \\
\hline
\end{tabular}

\section{SSM3 \&4 - System Model}

The PKLE systemigram provides a solid foundation for identifying and remediating existing weaknesses within participating systems. In this section, a discussion is provided on the existing relevant systems forming the enterprise and their interrelationships and possible weaknesses are identified.

The PKLE is a system of systems that is depicted in the systemigram as illustrated in Figure 2. It is divided into three main clusters of systems:

1. The home environment and supporting systems

2. The formal educational systems

3. The financial support system and its dependencies on economic conditions 


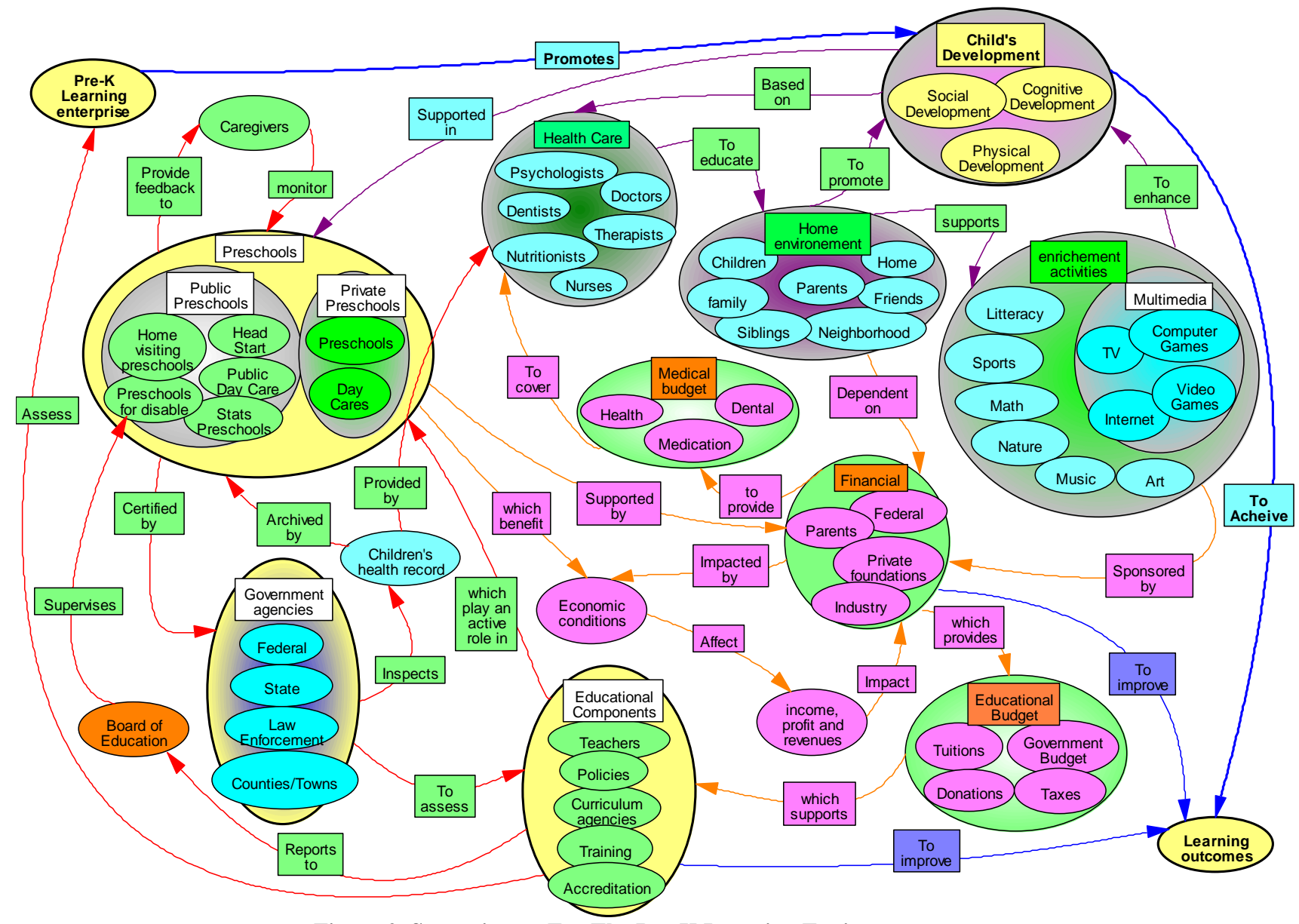

Figure 2. Systemigram For The Pre-K Learning Environment

Several factors influence children's development including: home environment and related interactions with parents, siblings, and peers; experiences in preschool; and a child's individual characteristics that include sex, age, race, and whether the child has special developmental needs [KID08]. According to several studies ([BAR07], [HAU97], [KAM07], [BAR95]], there are certain family attributes that play an important role in the development of young children including parental level of education, socio-economic status, parent-child interactions, and the family structure. Each of these factors can directly influence existing resources and home environment that either enhance or detract children's development [TRA93]. Parents and family form the foundation base of the child's initial learning experiences as the child becomes aware of her surroundings. Within the past century, parents' education as it relates to a child's early development and learning has become increasingly important [BAR07]. Accordingly, several books, handbooks, and other training manuals through various media (audio/video tapes, CDs, $\mathrm{TV}$, etc.) related to this subject have been developed along with seminars, workshops and newsletters that are offered to parents mostly in local township facilities such as libraries, city halls, and schools.

The Preschool environment is considered the primary establishment where children are exposed to formalized learning ([BEA97], [BAR95]). With today's fast changing innovative technologies and related industrial trends, schools are considered the main organization that forms the foundation for a child's development and learning. The school's educational systems, which include administration, teachers, curriculum and other related entities, are faced with an important challenge of producing highly effective learners who will have the capacity to resolve 21 st century problems. Early childhood education has been of high interest among researchers, educators, parents and government officials. Several studies in psychology, education, economics and social sciences have proven that early childhood programs have a long-term effect on cognitive development and school preparedness. 
Barnett [BAR95] reviews 36 studies to examine the long-term trends of early education programs and their effects on cognitive development. The review results indicate that early childhood programs can produce significant shortterm benefits for children on intelligence quotient (IQ) and sizable long-term effects on school achievement. However, according to the 2008 NIEER report [NIEER08], not all children in the US attend preschool. Home and preschool are not the only systems that are responsible for a child's development and learning as children are also highly influenced by the inside and outside environments that surround them. Children's health and nutrition are vital to the well being of the body and mind [HAU97]. Outdoor play that may include various activities such as playing in the playground, running, playing with sand, or just being outdoors is vital for a child's physical and psychological well being. Physical exercise including sports such as swimming, gymnastics, basketball etc., have been proven to be highly effective in enhancing a child's motor skills, concentration, and thinking process [HAU97]. Modern multimedia has a significant influence on children's learning through TV, personal computers, DVDs, video games, among others [HAU97]. Furthermore, local township libraries offer children activities that help them enhance their reading skills and expose them to scientific experiments, creative play, etc. Environmental centers also encourage families to participate in activities that contribute to a child's learning about nature and protecting the environment.

\section{SSM5 PKLE ENTERPRISE ANALYSIS}

\section{Causal Loops Diagrams CLDs}

In this section, Causal Loop Diagrams (CLDs) [SYT] are used to analyze the relevant variables and their relationships existing within the organizations that are represented in the systemigram of Figure 1. In the systems thinking approach, CLDs are commonly used as a useful tool to represent dynamic interrelationships between variables within a system. They provide a visual representation illustrating explicitly one's understanding of a system structure (they capture the mental model). Components of a CLD include:

\section{- Variables - an element in a situation which may act or be acted upon}

- They vary up or down over time (not an event)

- They are nouns or noun phrases (not action words)

- Links / Arrows - show the relationship and the direction of influence between variables

- $\quad$ S's and O's - show the way one variable moves or changes in relation to another

- S stands for "same direction"

- O stands for "opposite direction"

- Balancing feedback loop that seeks equilibrium

- $\quad$ Reinforcing feedback loop that amplifies change

While a balancing loop keeps the events in equilibrium (for example: if one is stressed, one does more exercise which reduces the stress level), the reinforcing loop creates an amplifying effect, which may lead to collapse (for example: The more stressed one is, the more tired one gets which in turn increases the stress level) [RIC86]. It can be shown that in a CLD, an odd number of "o's" in a loop indicates a balancing loop.

\section{Analysis Of PKLE Strengths}

It is shown from the systemigram in Figure 1 how much effort the government and state educational agencies make to promote early education especially for low-income families. This may offer their children a better learning environment at preschools and other facilities than the ones that are available in their homes and neighborhoods. Many efforts have been devoted to prepare children for kindergarten and beyond, and in exploiting 
the learning capacity of the young brain as suggested by early brain development research. While there are still some efforts that need to be done to assess and supervise public preschools, more needs to be devoted to educate parents and children on early age learning and development and the importance of early education.

Figure 3 illustrates that an increase in government involvement by opening more public preschools increases the demand and the number of children per class that may affect the educational quality that is offered. This may increase government involvement on adopting other strategies to offer better quality by providing more efforts to improve educational components (for example: defining better policies, hiring more teachers, adopting better curricula, etc). However, this may create a reinforcing loop that may grow exponentially and collapse where more educational components such as teachers' involvement to enhance educational quality to respond to the growing demand may reduce the government capacity to respond to such growth. Furthermore, several missing interactions that are related to a standardized curriculum in preschools, teachers training programs, and educational program assessment and evaluation are identified among preschools, government and educational components.

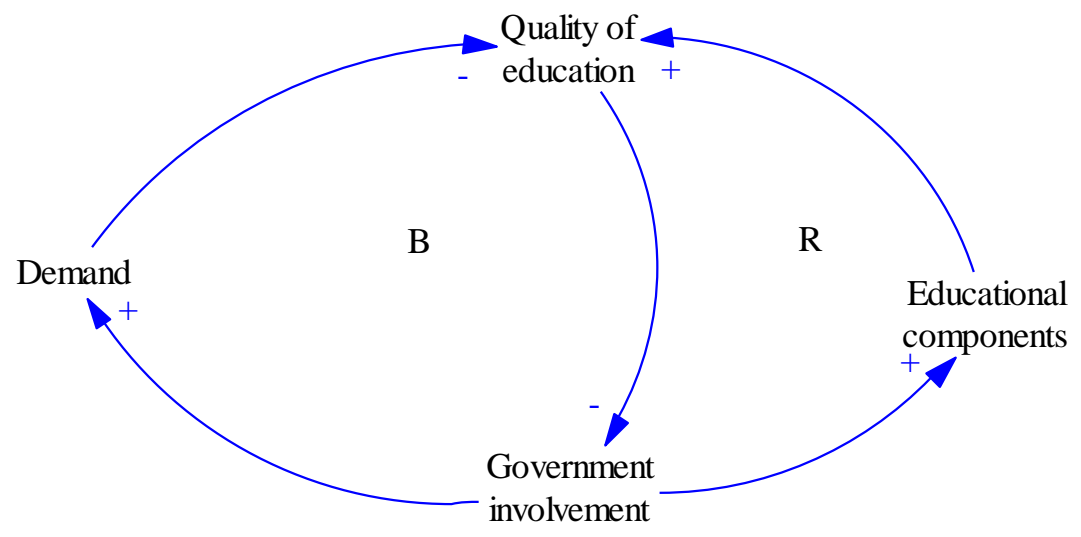

Figure 3. Government Involvement

Government enrichment supports mainly public preschools and overlooks the process of assessing their curriculum. Currently, private preschools have the freedom to choose different programs and educational methods including: Montessori, Piaget, and NAYC. They also have the freedom to choose whether to be accredited or not by the educational agencies whose accreditation fees are covered by the preschools. One could notice from the educational system modeled in Figure 3 that key interactions among private preschools, public preschools, and government are also missing, for example as they relate to the curriculum and exchanging effective methods and experiences to improve learning outcomes. Parents' involvement in curriculum assessment to improve quality education may be considered as an additional missing interrelationship.

\section{Analysis Of PKLE Weaknesses}

\section{Financial System}

As illustrated in Figure 1, the systemigram clearly shows the existing interrelationships among the various systems forming the pre-K learning enterprise. Among them, the dependence of several key systems on financial support is a predominant one. 


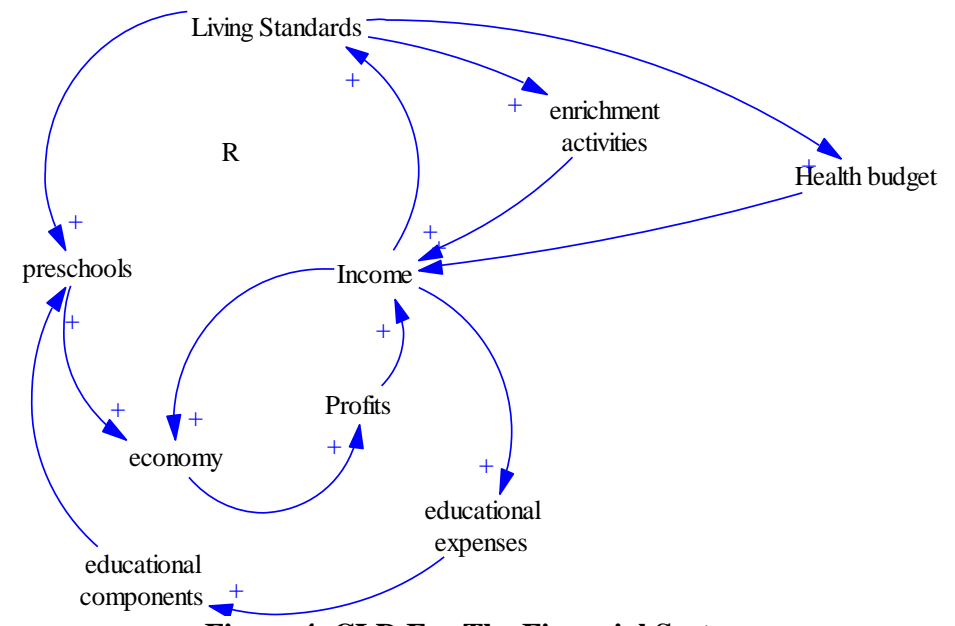

Figure 4. CLD For The Financial System

Figure 4 shows how each relevant variable within the financial system influences another such that the corresponding $C L D$ includes only reinforcing loops that could lead to unbounded growth and potential collapse. For example, "income" is a predominant variable that influences several other variables. High income is influenced by a healthy economy, which results in high profits for industry leading to higher salary increases and bonuses for parents. As a result of high income, higher contributions to educational tuition and donations would be expected allowing preschools to hire higher quality teachers, and provide enhanced training and educational components. Furthermore, higher income affects the family living standard in a positive way (i.e., better neighborhood with a better living standard including enhanced educational systems). Under these circumstances, average and highincome families have better chances of promoting effective child development by sending their children to private preschools and financing their education, health care expenses and enrichment activities.

Obviously, without appropriate financial support achievement of the desired learning outcomes would be limited to children of affluent families. In particular, parents and other financial resources depend on the economic conditions to support preschool children's tuition, health care, nutrition, and all other support activities. Public preschools are offered to eligible low-income families, which constrain other children to attend private preschools that are totally dependent on parents' support. Besides public libraries and some national environmental parks, most other educational centers such as museums, art centers, zoos, farms, enrichments activities are not free of charge.

\section{Home Environment}

The systemigram of Figure 1 also illustrates how the home environment is dependent on parents' education and awareness to support the learning environment. Parents' involvement is an essential element as they make the decisions for their children that get them exposed to the various learning systems including preschools, health care services, and support activities. A better education and awareness of caregivers on the importance of learning in children enhances their involvement on promoting more effective child developments which could reduce the need for increased involvement in preschools or for special education of children. Increased parents' involvement and interaction with teachers and health care providers will enhance their awareness and education. As shown in Figure 5 , enhanced awareness of caregivers forms balancing CLDs with the other relevant variables. 


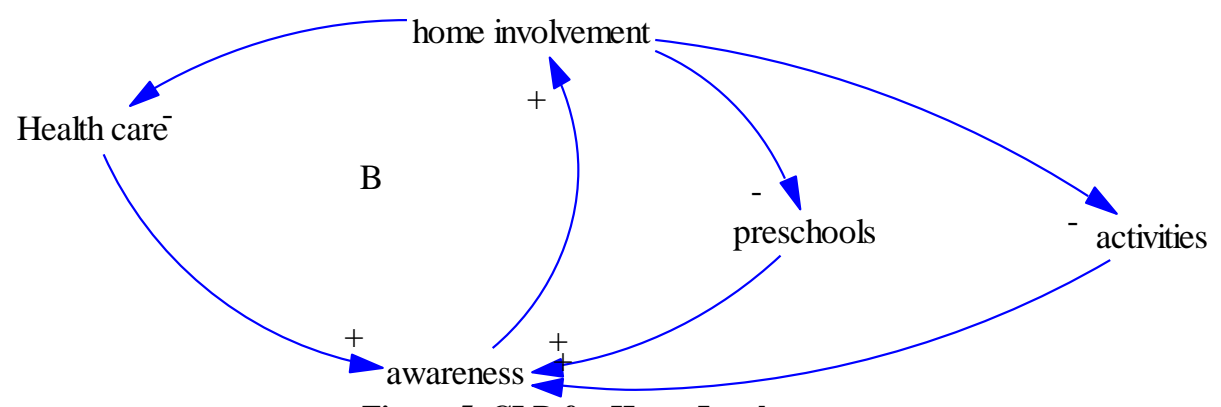

Figure 5. CLD for Home Involvement

The relationships between caregivers, preschools and health care on child development concepts could be reinforced for example by providing enhanced awareness material that could be shared between children and their families to enhance home involvement in children's education and health. As a result, when children receive a better education at home, it leads to reduced dependency on health care and preschool services.

Consequently, a learning environment starts at home, such that it is essential for parents to adopt effective strategies for children's education and their health. For example, the use of positive language with children is very important to develop listening and other developmental skills. Dr. Elissa Newport [NEW85], a social science researcher, reported in her study of deaf and spoken children that "If we look at the age when a learner is exposed to something and then look at ultimate competence, the age at which they do best is when there's a special sensitivity for learning". A lack of conversation with and attention to children, such as preference to having dinner in front of the television, is considered as conversation killers, which bring out tantrums in the best-behaved children [NEU03]. Furthermore, some studies show [NEU03] how today's children have less conversation at home with their caregivers and are more exposed to multimedia devices such as TV, electronic games and computers. This may reduce their listening skills and increase their misbehavior as Sue Palmer noted: "Forward-facing buggies - where parents don't talk to their children - the demise of the family meal, all-day television and the changes in parents' working habits have "alarming implications" for pupil behavior in the first few years of primary school". A study in the UK by the National Literacy Trust [SMI06] confirmed the danger of a lack of human interaction as they found in 2003 that $74 \%$ of head teachers were concerned of the deteriorations in language and listening skills, and again in 2005 they found $89 \%$ of preschool teachers were similarly concerned.

One could conclude that the balance and stability of home environment system is dependent on caregivers' awareness and willingness to be involved and devoted to children's learning.

\section{SSM6 Desirable And Proposed Changes}

As discussed above, among the various interactions between existing systems within the Pre-K learning enterprise as illustrated in the systemigram, important dependencies are indentified as they relate to:

1. Economical conditions, and financial sponsorship

2. Caregivers awareness on child's early education, health and well being of the children and their importance to the community and the economy

3. Government involvement in promoting education specifically for low-income families.

The state of the economy plays a major role as it affects the ability of entities forming the financial system (federal government, parents, industry, and private foundations) to provide educational, medical, and infrastructure budgets to related systems supporting the enterprise. Consequently, significant improvements to the existing enterprise could come from changes that would lead to reduced dependencies on the financial system as proposed below. Such changes would be even more important under adverse economic conditions. 
In spite of the large number of existing interactions among the various systems within the enterprise, some important ones are missing that could lead to improvements of the enterprise. They include:

1. Increased involvement of government with the home environment by implementing policies and regulations related to parents' education and their involvement in various aspects of their child's development and learning. A government program for a home support system specifically for low-income children that provides parents education on how to offer a better learning environment and increases their awareness might also highly beneficial.

2. Better access to information regarding the objectives and outcomes of the pre-K curriculum to allow parents to navigate through the curriculum via the Internet, newsletters, or any other media broadcast. This could allow parents to make their choices more effectively and become more involved in their children's education.

3. Enhanced interaction between government and preschools as it relates to curriculum standardization as well as assessment and evaluation of educational programs. Effective assessment methods to review learning outcomes and involve parents who can review their children educational needs could also be beneficial.

4. Standardization of the pre-K curriculum, though potentially controversial, may be beneficial towards implementing a common set of guidelines that would be derived from rigorous research studies of the most effective educational methods and curriculum content for enhanced pre-K learning.

5. Enhanced involvement of the health care system with preschools is another important improvement that might be achieved for example by providing visiting doctors, nurses, and dentists on a regular basis to educate children and teachers through preventive care workshops and provide basic medical testing periodically.

In addition to the remedial changes as proposed above, additional potential solutions that would lead the enterprise to be less dependent on the financial system are suggested as follows.

1. Partnerships among preschools are suggested to share/exchange various resources, which could lead to, reduced expenses and would lessen the reliance on the financial system.

2. A more effective awareness campaign on preventive care, health, and nutrition could be conducted by the Health Care system and government/state/city agencies on a regular basis to reduce the financial burden related to medical expenses.

3. A more effective awareness campaign for parents as it relates to children's education could enhance children's preparation for preschools and reduce the burden on the latter in providing quality education.

4. Partnerships between preschools and local private and public organizations offering enrichment activities (sports, art, literacy, music, multimedia, etc.) could also reduce the related expenses.

5. Partnerships among corporations who sponsor preschools for their employees could also be beneficial.

6. Revision of some of the state's standardization policies (for example low teachers-students ratios) may reduce costs for government and parents.

7. Increased parents' involvement with preschools by offering their voluntary services in various activities could reduce the burden on the schools.

\section{SSM7 Action To Improve The Problem Situation}

As discussed above, the parents' educational level as it relates to child development and learning environment is an important contributing system. Technological developments combined with demanding professional careers of the parents in a competitive environment have led to much less discussions between parents and their children, unhealthy meals, and more exposure to distracting multimedia, among others. Many efforts could be made through workshops, seminars, multimedia, and newsletters to make parents aware of effective methods for their children's learning and how to develop an effective learning environment at home. It has been shown that children who have good basic education at home perform better.

Other possible steps include increased involvement of the government toward the PKLE by enhancing the policies toward the curriculum offered as well as assessment and evaluation of educational programs. More reinforcement on children's healthcare awareness and its direct relationship to the child's physical, emotional and 
mental well-being could be helpful. This could be accomplished by providing nurses and psychologists visits to preschools to assess children and offer workshops to parents.

\section{CONCLUSIONS AND RECOMMENDATIONS}

A review of the literature revealed a significant lack of studies related to building a learning enterprise formed by existing learning organizations within the preschool environment. In the present study, using a systems thinking approach, the pre-K learning enterprise (PKLE) is developed for the first time and the various relationships that exist among the constituent systems and enterprise stakeholders are analyzed.

While the results of the PKLE analysis reveal an obvious heavy reliance on the financial system which affects the effectiveness of the PKLE, an analysis of the causal loops and related systemigram developed to model the PKLE led to several possible changes that could reduce the impact of this reliance leading to an overall enhancement of the PKLE and its learning outcomes. Proposed changes include: (1) enhancing the role of parents through better education on child development, learning, health and nutrition and their increased voluntary involvement with preschools, (2) reducing the dependency on the financial system by promoting partnerships among preschools, sports facilities, libraries and other learning systems to share resources, and (3) enhancing the government role's through implementation of curriculum standardization, assessment and evaluation, and of an effective policy towards mandatory education of low-income children.

To the authors' knowledge, the present study represents the first attempt in developing a detailed model of the pre-K learning enterprise based on the systems thinking approach. Future work includes developing a system model to validate the proposed solutions in order to build a balanced and sustainable PKLE.

\section{AUTHOR INFORMATION}

Kahina Lasfer is a PhD candidate in the School of Systems Engineering at Stevens Institute of Technology. Her research area is based on analyzing and creating a system's based approach for the graduate Systems engineering education for the $21^{\text {st }}$ century. She participated in many projects at the school of systems and enterprises including a project to create a model curriculum in graduate software engineering. She has a Masters degree in Computer Engineering. She worked with Lucent Technologies as a software developer and software designer/architect in embedded systems. She held other positions related to project management.

Art Pyster is a distinguished research professor at Stevens Institute of Technology and the deputy executive director of the Department of Defense Systems Engineering Research Center. During Dr. Pyster's 35 year career, he held several senior positions, including being the Senior Vice President and Director of Systems Engineering and Integration for SAIC and the Deputy Chief Information Officer for the U.S. Federal Aviation Administration. He is an INCOSE Fellow and a member of their board of directors. He currently runs BKCASE, a project that is establishing the body of knowledge for systems engineering together with guidelines for graduate programs in systems engineering.

Brian Sauser holds a B.S. from Texas A\&M University in Agricultural Development, a M.S. from Rutgers, The State University of New Jersey in Bioresource Engineering, and a Ph.D. from Stevens Institute of Technology in Project Management. He is currently an Assistant Professor in the School of Systems \& Enterprises at Stevens Institute of Technology. His research interest is in the management of system evolution and lifecycles and the advancement of a foundational science of systems thinking. He was the 2010 Davis Memorial Awardee for Research Excellence for his work in System Development Planning via System Maturity Optimization.

\section{REFERENCES}

1. [BAR95] W. Steven Barnett, Long Term Effects of Early Childhood Programs on cognitive and School Outcomes. The Future of Children Long-Term Outcomes of early childhood Programs Vol 5. No 3 Winter 95

2. [BAR07] W. Steve Barnett, Jason Hustedt and others, The State of Preschool, New Brunswick, N.J., 2007 
3. [BEA97] Barbara Beatty, Preschool Education in America, The Culture of Young Children from the Colonial Era to the Present. Yale University Press. September 1997

4. [BEE85] Beer, S. Diagnosing the system for Organizations, John Wiley, Chichester, 1985

5. [BOA08] John Boardman, Brian Sauser, Systems Thinking Coping with $21^{\text {st }}$ Century Problems, CRC Press, 2008

6. [CAP82] Fritjof Capra, The Turning Point - Science, Society and the Rising Culture, Wildwood House, London, 1982

7. [CAP99] Fritjof Capra, Ecoliteracy: The Challenge of Education in the Next Century, 1999, retrieved from http://www.ecoliteracy.org/publications/pdf/challenge.pdf on June 2008

8. [CHE90] Peter Checkland, Soft systems methodology in action, Wiley; New edition, 1999

9. [CHE81] Peter Checkland, Systems thinking, Systems Practice, Chichester: Wiley, 1999

10. [CHU79] West C. Churchman, The Systems Approach and Its Enemies, Basic Books, New York, 1979.

11. [DAH03] M. Dahms, K. Geonnotti, D. Passalacqua. J. N. Schilk, A. Wetzel, and M. Zulkowsky. The Educational Theory of Lev Vygotsky: retrieved from http://www.newfoundations.com/GALLERY/Vygotsky.html

12. [FLO99] Flood, R. Rethinking the Fifth Discipline - Learning within the unknowable, Routledge, London, 1999.

13. [FOR94] Forrester, J. Learning through system dynamics as preparation for the 21st century, 1994, retrieved from http://sysdyn.clexchange.org/sdep/papers/D-4434-3.pdf on June 2008

14. [GAL99] Gallagher, J., Rooney, R., \& Campbell, S., Child care licensing regulations and child care quality in four states; Early Childhood Research Quarterly, 14(3), 313-333, 1999.

15. [GIS08] Melinda Gish, Domestic Social Policy Division, Head Start: Background and Issues. CRS report number: RL30952. Published by United States Congressional Research Service. February 2, 2009

16. [HAU97] Robert Mason Hauser, Brett V. Brown, William R. Prosser, Indicators of children's well-being. Published by Russell Sage Foundation, 1997

17. [ISA08] Julia Isaac, Research Brief \#1: State Pre-Kindergarten, September 2008.

18. [KAG06] Kagan, S. L. American early childhood education: Preventing or perpetuating inequity? (Research Review No. 1). New York: Teachers College, Campaign for Educational Equity, 2006.

19. [KAG01] Kagan, S. L., Giving America's young children a better start: A change brief. Denver, CO: Education Commission of the States, 2001

20. [KAR05] Lynn A. Karoly, M. Rebecca Kilburn, Jill S. Cannon. Early childhood interventions: proven results, future promise. Published by Rand Corporation, 2005

21. [KAM07] Kamerman, S. B. \& Gatenio Gabel, S.; Early childhood education and care in the United States: An overview of the current policy picture. International Journal of Child Care and Education Policy, 1(1), November 2007

22. [KID08] Kids Count http://www.aecf.org/MajorInitiatives/KIDSCOUNT.aspx

23. [MAC08] Mackenzie Ryan, Most vital part of education takes place early: Child's first five years, 2008.

24. [NAE96] NAEYC - http://www.naeyc.org/

25. [NEU03] Susan B. Neuman, David K. Dickinson, Handbook of early literacy research, Published by Guilford Press, 2006

26. [NIEER07] National Institute for Early Education Research (NIEER), 2007), http://nieer.org/yearbook/.

27. [PIA69] Piaget, J.; The Psychology of the Child. Published by Basic Books, 1969

28. [PRK]Pre-K Now, Pre-K Across the Country, http://preknow.org/policy/factsheets/snapshot.cfm

29. [RIC86] Richardson, G.P. 1986/1976. Problems with Causal Loop Diagrams. System Dynamics Review 2,2 (summer): 158-170.

30. [SAN09] Adolfo Sánchez; Andrés Mejía, Learning to support learning together: an experience with the soft systems methodology, Educational Action Research, 1747-5074, Volume 16, Issue 1, 2008, Pages 109 124

31. [SEN90] Senge, P. M.; The Fifth Discipline: The Art and Practice of the Learning Organization, New York: Currency Doubleday, 1990.

32. [SCO05] Scott-Little, C. \& Al.; Creating the Conditions for Success with Early Learning Standards: Results from a National Study of State-Level Standards for Children's Learning Prior to Kindergarten, ECRP , Fall 2005, Vol5, n 2, retrieved from http://www.peelearlyyears.com/pdf/Creating the Conditions for Success\% 20with Early Learning.pdf 
33. [SMI06] Alexandra Smith, Parents urged to talk more to their children, Monday 3 April 2006. Retrieved from http://www.guardian.co.uk/education/2006/apr/03/schools.uk3

34. [SYT] The Systems Thinker Cambridge, MA: Pegasus Communications. http://www.thesystemsthinker.com/tstgdlines.html

35. [THO08] Ross A. Thompson; Connecting Neurons concepts and People. Brain Development, and People; a series of briefs developed by the National Institute for Early Education Research, issue 17, 2007, retrieved on august 2008 from nieer.org.

36. [TRA93] Summers Tracey, Increasing parents involvement in children's education through awareness workshops. Mid South educational Research Association, November 1993.

37. [VYG87] Vygotsky, L.S., The Collected Works of L. S. Vygotsky. Volume 1: Problems of General Psychology, Translated and with an Introduction by Norris Minick. Editors of the English translation: R. W. Rieber and A.S. Carton. New York: Plenum Press, 1987. 